\title{
Erratum to: Evaluation of Caustic Embrittlement Susceptibility of Steels by Slow Strain Rate Testing
}

\author{
R.K. SINGH RAMAN
}

DOI: $10.1007 / \mathrm{s} 11661-017-4326-0$

(C) The Minerals, Metals \& Materials Society and ASM International 2017

Erratum to: METALLURGICAL AND MATERIALS

TRANSACTIONS A, Volume 36A, July

2005, pp. 1817-1823

DOI: 10.1007/s11661-005-0045-z

DUE to an error by the author, the reference R.K. Singh Raman, A. Kouklan, and G.P. Simon: Proceedings (CDROM) Corrosion and Protection Conf., Perth, Australia, Paper no. 25, Australian Corrosion Association, 2004, pp. 1-6 should have been included in the list of references as well as cited as a source of the data in Figures 2-7 and Table 1.

R.K. SINGH RAMAN, Senior Research Fellow, is with the School of Physics and Materials Engineering, Monash University, Melbourne, Victoria 3800, Australia. Contact e-mail: raman.singh@monash.edu

The online version of the original article can be found under doi: 10.1007/s11661-005-0045-z.

Article published online September 18, 2017 